\title{
Influence of operative strategy for the aortic arch in DeBakey type I aortic dissection: Analysis of the German Registry for Acute Aortic Dissection Type A
}

\author{
Jerry Easo, MD, ${ }^{\mathrm{a}}$ Ernst Weigang, MD, PhD, ${ }^{\mathrm{b}}$ Philipp P. F. Hölzl, MD, ${ }^{\mathrm{a}}$ Michael Horst, MD, ${ }^{\mathrm{a}}$ \\ Isabell Hoffmann, MS, ${ }^{\mathrm{c}}$ Maria Blettner, $\mathrm{MS}, \mathrm{PhD},{ }^{\mathrm{c}}$ and Otto E. Dapunt, $\mathrm{MD}, \mathrm{PhD},{ }^{\mathrm{a}}$ for the GERAADA \\ study group
}

\begin{abstract}
Objective: Patients treated with an extensive approach including total aortic arch replacement for acute aortic dissection type A may have a favorable long-term prognosis by treating the residual false lumen. Our goal was to analyze the operative strategy for treatment of type I DeBakey aortic dissection from the German Registry for Acute Aortic Dissection Type A (GERAADA) data.
\end{abstract}

\begin{abstract}
Methods: A total of 658 patients with type I DeBakey aortic dissection and entry only in the ascending aorta were identified in the GERAADA. Patients in group A underwent replacement of the ascending aorta with hemiarch replacement. Patients in group B received extensive treatment with total arch replacement or conventional or frozen elephant trunk.
\end{abstract}

\begin{abstract}
Results: A total of 518 patients in group A and 140 patients in group B were treated. There was an overall 30-day mortality of $20.2 \%(n=133)$. Group A had a slightly lower rate of mortality with $18.7 \%(n=97)$ compared with $25.7 \%$ for group B $(\mathrm{n}=36)$, but with no statistical significant difference $(P=.067)$. The onset of new neurologic deficit $(13.6 \%$ in group vs $12.5 \%$ in group $\mathrm{B}, P=.78)$ and new malperfusion deficit $(8.4 \%$ in group A vs $10.7 \%$ in group $\mathrm{B}, P=.53$ ) showed no statistical difference.
\end{abstract}

Conclusions: On analysis of the GERAADA data, it seems that a more aggressive approach of aortic arch treatment can be applied without higher perioperative risk even in the onset of acute aortic dissection type A. Long-term follow-up data analysis will be necessary to offer the optimal surgical strategy for different patient groups. (J Thorac Cardiovasc Surg 2012;144:617-23)

Acute aortic dissection type A (AADA) remains a challenging condition to manage. Despite improvements in preoperative diagnosis, surgical technique, and patient care, early mortality and morbidity remain high. ${ }^{1}$ Conventional treatment for acute dissection is replacement of the ascending aorta often combined with a hemiarch replacement; however, this treatment leaves the downstream aorta untouched, and a residually dissected aorta has been demonstrated in up to $70 \%$ of patients. ${ }^{2-6}$ Because the residual dissection of the descending aorta carries the risk of progressive aneurysmal dilation, ${ }^{7}$ subsequent aortic reintervention of the descending aorta may be necessary, influencing the long-term benefits of the initial surgery. ${ }^{8-10}$ A more aggressive initial

\footnotetext{
From the Department of Cardiothoracic and Vascular Surgery, ${ }^{a}$ Klinikum Oldenburg, Germany; Department of Cardiothoracic and Vascular Surgery, ${ }^{\mathrm{b}}$ Medical Centre of the Johannes Gutenberg University Mainz, Germany; and Institute for Medical Biostatistics, Epidemiology and Informatics, ${ }^{\mathrm{c}}$ Medical Centre of the Johannes Gutenberg University Mainz, Germany.

Disclosures: Authors have nothing to disclose with regard to commercial support.

Jerry Easo and Ernst Weigang contributed equally to the article.

Received for publication June 4, 2011; revisions received July 13, 2011; accepted for publication July 27, 2011; available ahead of print Nov 18, 2011

Address for reprints: Jerry Easo, MD, Department of Cardiothoracic Surgery, Klinikum Oldenburg, Rahel Straus Str 10, 26133 Oldenburg, Germany (E-mail: easo. jerry@klinikum-oldenburg.de).

$0022-5223 / \$ 36.00$

Copyright (c) 2012 by The American Association for Thoracic Surgery

doi:10.1016/j.jtcvs.2011.07.066
}

treatment with total arch repair, possibly with adjunct therapy of the descending aorta obliterating the false lumen, is propagated by several groups to decrease the incidence of late aortic complications. ${ }^{11-13}$ However, other groups have demonstrated an increased risk of morbidity and mortality with extensive surgery of the downstream aorta, thus recommending a more conservative strategy limited to the ascending aorta and proximal arch. ${ }^{14-16}$

The German Registry for Acute Aortic Dissection Type A (GERAADA) is a web-based registry, initiated by the Working Group for Aortic Surgery and Interventional Vascular Surgery of the German Society for Thoracic and Cardiovascular Surgery. The GERAADA is presently the largest registry worldwide documenting patients undergoing surgery for AADA. ${ }^{17-20}$ Analysis of the GERAADA gave us the opportunity to perform large cohort analyses of patients treated for DeBakey type I aortic dissection to compare the surgical outcome of patients treated by total arch replacement with those of hemiarch replacement with respect to early mortality and onset of new neurologic and malperfusion deficit.

\section{MATERIALS AND METHODS \\ Patients}

We analyzed all patients with AADA enrolled between July 2006 and June 2010 in the GERAADA. The structure of this web-based registry has 


\section{Abbreviations and Acronyms \\ AADA = acute aortic dissection type A \\ FET $\quad=$ frozen elephant trunk \\ GERAADA $=$ German Registry for Acute Aortic Dissection Type A \\ ICU = intensive care unit}

been described. ${ }^{17,18}$ All patients with DeBakey type I aortic dissection were included, that is, a dissection of the ascending aorta extending over the aortic arch and involving the descending aorta. The localization of the intimal entry tear had to be limited to the ascending aorta. Patients demonstrating a tear (entry or reentry) of the transverse arch requiring a total or subtotal arch replacement were excluded from this cohort analysis. These patients were then divided into 2 groups. Group A had conventional treatment with replacement of the ascending aorta performed resecting the intimal tear. If necessary, treatment of the aortic valve was performed by valve resuspension, root reconstruction, or valve replacement. Hemiarch replacement was performed in a period of circulatory arrest with an open distal anastomosis. Group B had a more extensive surgery performed with total arch replacement, possibly in combination with an elephant trunk or frozen elephant trunk (FET) procedure.

\section{Definition}

Total arch replacement was defined as involving the total aortic arch with reimplantation of the supra-aortic vessels as an island or as individual branch grafts. Hemiarch replacement included the aortic arch beyond the level of the innominate artery with or without reimplantation of the arch vessels.

Neurologic deficit was defined as the presence of stroke, hemiparesis, paraparesis, aphasia, or coma. Malperfusion deficit was defined as signs attributable to disturbed blood flow to end-organ systems, such as myocardial, visceral, or peripheral limb malperfusion. Excessive bleeding was defined as more than $1000 \mathrm{~mL}$ over the initial 24-hour period.

\section{Data Collection}

Data were acquired by use of a standard online questionnaire developed by the GERAADA principal investigator. Data collected included patient demographics, preoperative and intraoperative status, postoperative complications, early results, and date of death. Data forms were delivered to the registry on the German Society for Thoracic and Cardiovascular Surgery homepage (available at: http://www.dgthg.de).

\section{Statistical Analysis}

Statistics are summarized as frequencies and percentages for categoric variables and as mean and standard deviation for continuous variables. Differences in baseline characteristics between patients who underwent total arch replacement or hemiarch replacement were compared using the $t$ test or the Mann-Whitney $U$ test for continuous variables and the chisquare test or Fisher exact test for categoric variables as appropriate. The descriptive statistics and tests have been analyzed referring to cases without missing values (complete case analysis). Influence of risk factors onto 30day mortality, new neurologic deficit, and new malperfusion deficit were analyzed using logistic regression analysis. These factors included age; presence of aortic aneurysm; clinical presentation, such as necessary inotrope medication, preoperative cardiopulmonary resuscitation, pericardial tamponade, preoperative neurologic deficit, and preoperative malperfusion deficit; gender; and operative data, such as length of cardiopulmonary bypass, aortic clamp time, length of circulatory arrest, and cerebral perfusion.
}

\section{RESULTS}

Between July 2006 and June 2010, 50 centers participating in the GERAADA reported on 2137 patients. From this complete patient cohort, a subgroup of 658 patients was identified with a DeBakey type I aortic dissection and entry limited to the ascending aorta. All patients with an entry or reentry in the transverse arch or proximal descending aorta were excluded from the study. A total of 518 patients had replacement of the ascending aorta performed with a hemiarch replacement, and 140 patients had a more extensive and radical approach with total arch replacement, some with treatment of the descending aorta with the elephant trunk or FET procedure. Table 1 describes patient demographics, cause, clinical presentation, and imaging of patients with AADA. A total of 172 patients presented with an existing neurologic deficit preoperatively (26.1\%; group A, $24.7 \%$ vs group B, $31.4 \%$ ), and 261 patients presented with a preoperative malperfusion deficit (39.7\%; group A, $38.2 \%$ vs group $\mathrm{B}, 46.4 \%$ ).

The mean age of group A was $59.1 \pm 13.3$ years, similar to group B with a mean age of $58.3 \pm 11.9$ years. In group A, $62.6 \%$ were male, and in group B, $61.4 \%$ were male. Connective tissue disorders were rare, most patients presented with arterial hypertension, $26.5 \%$ of group A had an aortic aneurysm, $35.7 \%$ of group B presented with an aortic aneurysm $(P=.03)$. Patients in group $\mathrm{B}$ had a higher frequency of cardiopulmonary resuscitation $(P=.04)$; otherwise, the patients presented with relatively similar clinical conditions. Most patients were diagnosed by computed tomography and echocardiography; significantly more patients in group $\mathrm{B}$ had a diagnosis performed by echocardiography $(P=.007)$ and angiography $(P=.014)$.

All patients underwent surgery via a median sternotomy and cardiopulmonary bypass. The operative procedure was significantly shorter with hemiarch replacement (318.1 \pm 104.4 minutes) than with total arch replacement (390.4 \pm $137.3 \mathrm{~min}, P<.001$ ), and the mean time of circulatory arrest was shorter for group A than for group B $(24.3 \pm 14.4$ minutes vs $44.8 \pm 29.7$ minutes, $P<.001)$. Further details are demonstrated in Table 2. The postoperative outcome showed a higher rate of rethoracotomy for group B $(18.5 \%$ vs $28.6 \%, P=.013)$ and a higher rate of bleeding $(22.3 \%$ vs $35.7 \%, P=.002)$. In group $\mathrm{B}$, the postoperative intensive care unit (ICU) length of stay was longer $(8.1 \pm$ 11.3 days vs $10.3 \pm 13.8$ days, $P<.001)$ and the hospital stay was longer $(16.3 \pm 14.6$ days vs $17.1 \pm 16.1$ days, $P<.001)$.

The onset of new neurologic deficit showed no difference between the 2 groups ( $13.6 \%$ vs $12.5 \%, P=.78$ ). Patients with a preexisting neurologic deficit $(\mathrm{n}=128$ in group A and $n=44$ in group B) were excluded from this analysis. The preoperative neurologic condition showed no influence on the type of surgery performed $(24.7 \%$ vs $31.4 \%$, 
TABLE 1. Demographics, cause, clinical presentation, and diagnostic imaging

\begin{tabular}{lccc}
\hline \multicolumn{1}{c}{ Variable } & $\begin{array}{c}\text { Group A } \\
\mathbf{n}=\mathbf{5 1 8}\end{array}$ & $\begin{array}{c}\text { Group B } \\
\mathbf{n = 1 4 0}\end{array}$ & $\boldsymbol{P}$ \\
\hline Clinical characteristics & & & \\
Age (y) & $59.1 \pm 13.3$ & $58.3 \pm 11.9$ & \\
Gender: male & $324(62.6 \%)$ & $86(61.4 \%)$ & .84 \\
Cause & & & \\
Arterial hypertension & $283(54.6 \%)$ & $88(62.9 \%)$ & .08 \\
Aortic aneurysm & $137(26.5 \%)$ & $50(35.7 \%)$ & .03 \\
Clinical presentation & & & \\
Cardiac tamponade & $101(19.5 \%)$ & $36(25.7 \%)$ & .12 \\
Cardiopulmonary resuscitation & $26(5.1 \%)$ & $14(10 \%)$ & .04 \\
Intubated by admission & $87(16.8 \%)$ & $23(16.4 \%)$ & 1 \\
Hemiplegia or hemiparesis & $50(9.7 \%)$ & $14(10 \%)$ & .87 \\
Paraplegia or paraparesis & $24(4.63 \%)$ & $12(8.6 \%)$ & .09 \\
Aphasia & $13(2.5 \%)$ & $2(1.4 \%)$ & .74 \\
Diagnostic imaging & & & \\
Computed tomography & $465(89.8 \%)$ & $123(87.7 \%)$ & .54 \\
Echocardiography & $232(44.8 \%)$ & $81(57.9 \%)$ & .007 \\
Angiography & $35(6.7 \%)$ & $19(13.6 \%)$ & .014 \\
Magnetic resonance & $11(2.1 \%)$ & $4(2.9 \%)$ & .53 \\
\hline
\end{tabular}

$P=.11)$. The presence of preoperative neurologic deficit showed no difference in postoperative mortality $(32.8 \%$ vs $29.5 \%, P=.69$ ); however, if patients underwent surgery without a preexisting neurologic deficit, group A demonstrated a lower risk of mortality than group B with the more extensive procedure $(14.1 \%$ vs $24 \%, P=.02)$. A McNemar's test was performed investigating the influence of surgical procedure on the reduction of existing preoperative neurologic deficits; however, there were no significant differences to be seen.

Likewise, the analysis was performed for malperfusion. The onset of new malperfusion showed no significant difference $(8.4 \%$ vs $10.7 \%, P=.53)$. Postoperative mortality in patients with preoperative malperfusion was similar ( $25.5 \%$ vs $33.8 \%, P=.19)$; in the absence of preoperative malperfusion, there was no significant difference $(14.6 \%$ vs $18.7 \%, P=.37$ )

Overall mortality was 133 patients $(20.2 \%)$, with a tendency to a lower rate of mortality in group A $(18.7 \%)$ than in group B $(25.7 \%)$, but without significant statistical difference $(P=.07)$.

Logistic regression analysis of clinical presentation and surgery on 30-day mortality showed age $(P=.0072)$, preoperative resuscitation $(P=.041)$, length of cerebral perfusion $(P=.0122)$, and length of circulatory arrest $(P=.041)$ to be significant risk factors for early postoperative mortality (Table 3). Regression analysis investigating the influence of the type of surgery chosen demonstrated more extensive surgery with total arch replacement, but this was not a significant risk factor for the 30-day mortality $(P=.11)$. Logistic regression analysis of clinical presentation and surgery for the onset of new neurologic deficit
TABLE 2. Surgical procedure and early postoperative outcome

\begin{tabular}{lccc}
\hline \multicolumn{1}{c}{ Variable } & Group A & Group B & \\
& $\mathbf{n}=\mathbf{5 1 8}$ & $\mathbf{n = 1 4 0}$ & $\boldsymbol{P}$ \\
\hline Surgical procedures & & & \\
Mean operative time (min) & $318.1 \pm 104.4$ & $390.4 \pm 137.3$ & $<.001$ \\
Mean circulatory arrest time & $24.3 \pm 14.4$ & $44.8 \pm 29.7$ & $<.001$ \\
$\quad($ min) & & & \\
Degree of hypothermia $\left({ }^{\circ} \mathrm{C}\right)$ & $23.1 \pm 4.1$ & $23 \pm 3.8$ & \\
Selective cerebral perfusion & $347(67 \%)$ & $118(84.2 \%)$ & $<.001$ \\
Ascending aortic & $367(70.9 \%)$ & $89(63.6 \%)$ & .09 \\
$\quad$ replacement & & & \\
Composite graft replacement & $110(21.2 \%)$ & $39(27.9 \%)$ & .11 \\
David operation & $33(6.4 \%)$ & $12(8.6 \%)$ & .34 \\
Yacoub operation & $10(1.9 \%)$ & $5(3.6 \%)$ & .33 \\
Elephant trunk & 0 & $48(34.3)$ & $<.001$ \\
CABG & $49(9.5 \%)$ & $15(10.7 \%)$ & .63 \\
Valve replacement/repair & $113(21.8 \%)$ & $41(29.2 \%)$ & .07 \\
Outcome & & & \\
Rethoracotomy & $96(18.5 \%)$ & $40(28.6 \%)$ & .013 \\
Bleeding (>1000 mL) & $116(22.3 \%)$ & $50(35.7 \%)$ & .002 \\
New incidence of neurology & $53(13.6 \%)$ & $12(12.5 \%)$ & .78 \\
New incidence of & $27(8.4 \%)$ & $8(10.7 \%)$ & .53 \\
$\quad$ malperfusion & & & \\
ICU length of stay (d) & $8.1 \pm 11.3$ & $10.3 \pm 13.8$ & $<.001$ \\
Hospital length of stay (d) & $16.3 \pm 14.6$ & $17.1 \pm 16.1$ & $<.001$ \\
\hline CABG Coronay & & &
\end{tabular}

$C A B G$, Coronary artery bypass grafting.

showed no significant risk factors (Table 3). A logistic regression analysis for the onset of new malperfusion deficit demonstrated aortic aneurysm $(P=.023)$, length of cerebral perfusion $(P=.0064)$, and length of circulatory arrest $(P=.021)$ to be risk factors (Table 3$)$.

\section{DISCUSSION}

The long-term benefits of the surgical treatment for AADA may be influenced by the presence of a patent false lumen of the untreated descending aorta, seen in up to $70 \%$ of patients treated for AADA. ${ }^{1}$ The residually dissected downstream aorta has been shown to be a significant risk factor for descending aortic aneurysm formation. ${ }^{7}$ Because anastomotic leakage or small tears in the descending aorta can exist after replacement of the ascending aorta or hemiarch, the false lumen is susceptible to dilation because of shear stress acting on the proximal descending aorta. ${ }^{13}$ In previous studies, aneurysmal dilation occurred in $15 \%$ to $60 \%$ within 10 years, ${ }^{2,5,6}$ and as many as $25 \%$ required second surgery within 5 to 10 years., ${ }^{3,4,21}$

Several groups propagate a more extensive approach for the treatment of AADA with total arch replacement to decrease the prevalence of a patent false lumen by maximizing the resection of entry tears. ${ }^{11,22-24}$ Kazui and colleagues ${ }^{11}$ reported subsequent dilation of the most susceptible parts of the false lumen to be prevented when the descending aorta was repaired up to the mid-portion using the elephant trunk technique. The clinical data presented show excellent 
TABLE 3. Binary logistic regression analysis for 30-day mortality, new neurologic deficit, and new malperfusion deficit

\begin{tabular}{|c|c|c|c|}
\hline Variable & OR & $95 \% \mathrm{CI}$ & $\boldsymbol{P}$ \\
\hline \multicolumn{4}{|l|}{ 30-d mortality for all patients } \\
\hline Age* & 1.05 & $1.01-1.08$ & .0072 \\
\hline Aortic aneurysm & 0.74 & $0.32-1.72$ & .48 \\
\hline Preoperative resuscitation & 4.99 & $1.07-23.20$ & .04 \\
\hline Preoperative inotrope medication & 1.21 & $0.41-3.58$ & .74 \\
\hline Pericardial tamponade & 2.12 & $0.8-5.65$ & .13 \\
\hline Gender & 1.15 & $0.53-2.51$ & .71 \\
\hline Operative time $\dagger$ & 1.01 & $0.99-1.01$ & .11 \\
\hline Cardiopulmonary bypass time $\dagger$ & 1.01 & $0.99-1.01$ & .18 \\
\hline Aortic clamp time $\dagger$ & 1.01 & $0.99-1.01$ & .69 \\
\hline Length of cerebral perfusion $\dagger$ & 0.95 & $0.92-0.99$ & .01 \\
\hline Length of circulatory arrest $\dagger$ & 1.04 & $1.00-1.07$ & .04 \\
\hline Hemiarch replacement & 0.49 & $0.20-1.2$ & .11 \\
\hline \multicolumn{4}{|l|}{ New neurologic deficit } \\
\hline Age* & 1 & $0.97-1.03$ & .73 \\
\hline Aortic aneurysm & 0.38 & $0.15-0.99$ & .05 \\
\hline Preoperative resuscitation & 2.58 & $0.57-11.67$ & .22 \\
\hline Preoperative inotrope medication & 1.36 & $0.47-3.95$ & .58 \\
\hline Pericardial tamponade & 1.02 & $0.36-2.88$ & .97 \\
\hline Gender & 1.29 & $0.63-2.66$ & .49 \\
\hline Operative time $\dagger$ & 1.00 & $0.99-1.01$ & .54 \\
\hline Cardiopulmonary bypass time $\dagger$ & 0.99 & $0.99-1.01$ & .62 \\
\hline Aortic clamp time $\dagger$ & 1.0 & $0.99-1.01$ & .44 \\
\hline Length of cerebral perfusion $\dagger$ & 1.0 & $0.98-1.02$ & .90 \\
\hline Length of circulatory arrest $\dagger$ & 0.99 & $0.97-1.02$ & .56 \\
\hline Hemiarch replacement & 1.16 & 048.-2.79 & .73 \\
\hline \multicolumn{4}{|l|}{ New malperfusion deficit } \\
\hline Age* & 1.02 & $0.99-1.06$ & .24 \\
\hline Aortic aneurysm & 0.26 & $0.083-0.084$ & .02 \\
\hline Preoperative resuscitation & 3.75 & $0.59-23.96$ & .16 \\
\hline Preoperative inotrope medication & 0.59 & $0.15-2.27$ & .43 \\
\hline Pericardial tamponade & 3.03 & $0.99-9.26$ & .05 \\
\hline Gender & 1.14 & $0.47-2.79$ & .77 \\
\hline Operative time $\dagger$ & 1.01 & $1.00-1.01$ & .10 \\
\hline Cardiopulmonary bypass time $\dagger$ & 1.0 & $1.00-1.01$ & .33 \\
\hline Aortic clamp time $\dagger$ & 0.99 & $0.98-1.0$ & .06 \\
\hline Length of cerebral perfusion $\dagger$ & 0.93 & $0.88-0.98$ & .006 \\
\hline Length of circulatory arrest $\dagger$ & 1.06 & $1.01-1.12$ & .02 \\
\hline Hemiarch replacement & 0.3 & $0.10-0.86$ & .02 \\
\hline
\end{tabular}

$O R$, Odds ratio; $C I$, confidence interval. *OR calculated over a 5-year time interval. $\dagger$ OR calculated over 60-minute time intervals.

operative results with a low rate of mortality. Patients who underwent total arch replacement showed a more favorable outcome in terms of progressive aortic enlargement than those with only ascending aorta and hemiarch replacement. ${ }^{13}$ Other surgeons advocated insertion of a small elephant trunk during replacement of the aortic arch to exclude small intimal tears adjacent to the anastomosis. ${ }^{25}$ Complete thrombosis of the false lumen in the proximal descending aorta was achieved in $43.2 \%$ of patients at discharge and in $100 \%$ of patients at 3 years after treatment for AAD surgery. ${ }^{26}$
Several groups propagate an even more aggressive treatment in the setting of AADA, with an antegrade stenting of the descending aorta over the open aortic arch in circulatory arrest using the FET technique. Uchida and colleagues ${ }^{13}$ performed the FET procedure in patients aged less than 70 years with AADA and obtained good long-term results; the procedure was also selected for patients with a narrowing of the true lumen, which may lead to malperfusion of the visceral branches. ${ }^{13}$ In-hospital mortality for the FET technique was excellent at $4.6 \%$. Long-term results demonstrated a survival of $95.3 \%$ at 5 years and an event-free rate of $95.7 \%$ at 5 years compared with $73.0 \%$ for patients with hemiarch replacement for AADA. Tsagakis and colleagues $^{27}$ also demonstrated good operative results with an in-hospital mortality of $12 \%$ and $92 \%$ immediate false lumen thrombosis in the perigraft stent level for AADA with the use of the Evita Open prosthesis. ${ }^{27}$

These results encourage the more extensive and radical approach for treatment for AADA, but at the cost of a more invasive and complicated surgical procedure. The longer periods of myocardial ischemia and circulatory arrest are inevitable in extensive arch surgery directly related to cardiac and cerebral injuries, as well as organ dysfunction. Concomitant distal aortic arch manipulation has been demonstrated to increase the risk of mortality and morbidity by several groups. ${ }^{14-16}$ Furthermore, various studies have documented the natural course of the dissected descending aorta after AADA. Sabik and colleagues ${ }^{28}$ showed that the residual dissected aorta did not decrease late survival and demonstrated a low risk of aneurysmal change and reoperations for at least 10 years. Crawford and colleagues ${ }^{14}$ showed $70 \%$ of surviving patients with DeBakey type I dissection did not have a second aortic operation for aneurysmal dilation of the distal false channel, but this did not include the patients in whom an intimal tear in the transverse aortic arch was included in the resection. Dobrilovic and Elefteriades ${ }^{29}$ demonstrated a need for reoperation in only $2 \%$ of patients for dilation of the descending aorta after analysis of the Yale Center for Thoracic Aortic Disease database, with a growth rate of only $0.28 \mathrm{~cm}$ per year. Kim and colleagues ${ }^{30}$ recently described a poorer survival and neurologic outcome for patients with total arch replacement. In their study, the rate of reoperation was not affected by the type of surgery for AADA, and the reoperations were performed without significant mortality or morbidity.

It is clear that the controversial data setting confuses choosing the optimal therapeutic regimen for treatment of this life-threatening disease. Clinical studies to date have limitations with small patient groups and biased patient selection influencing postoperative results and their interpretation. Use of the GERAADA, the largest worldwide registry for the treatment of AADA, allowed us to analyze a large patient cohort focusing on the influence of the 
operative strategy chosen for the aortic arch and its influence on mortality, as well as the onset of new neurologic and malperfusion deficit.

Postoperative mortality was $20.2 \%$ for patients with DeBakey type I dissection in the GERAADA. A tendency for lower postoperative mortality in those receiving hemiarch replacement compared with total arch replacement $(18.7 \%$ vs $25.7 \%)$ fails to be statistically significant; however, the less aggressive procedure is favored. The analysis investigating intra- and postoperative data shows results comparable to data provided by other groups investigating outcomes after surgery for AADA. ${ }^{31}$ Patients treated for AADA often have a complicated postoperative recovery; age, renal failure, prolonged hypothermic circulatory arrest, and postoperative pulmonary dysfunction are some of the risk factors for prolonged ICU stay and predictors of mortality. ${ }^{32}$ This may be a reason for the relatively long period of re-convalescence, reflected by the long period of ICU and hospital stays. Higher rates of rethoracotomy $(P=.013)$ and excessive bleeding $(>1000 \mathrm{~mL} / \mathrm{d})(P=.002)$ demonstrate the postoperative complications caused by the coagulopathic disorders induced by hypothermia and influence the length of ICU and hospital stays.

Cerebral perfusion deficit has been demonstrated to be a major risk factor in $\mathrm{AADA}^{32-34}$ and is often a reason for delaying surgical repair. The onset of new neurologic deficit shows no difference between the hemiarch and total arch groups $(13.6 \%$ vs $12.5 \%, P=.78)$, unlike the findings of Kim and colleagues ${ }^{30}$ of more frequent neurologic dysfunction in patients receiving total arch replacement. Overall onset of neurologic dysfunction is similar to that in other reports, with $13.4 \%$ after surgery. Uchida and colleagues ${ }^{13}$ described excellent results with no new cerebral deficits and spinal cord injury postoperatively. The GERAADA, with 50 heart centers with different experience in aortic surgery involved, could not reproduce such results. Kim and colleagues ${ }^{30}$ describe complications with new onset of neurologic dysfunction in $31.4 \%$, and Kallenbach and colleagues ${ }^{35}$ demonstrated neurologic complications in $22 \%$ of 295 patients treated for AADA in Hannover. Further analysis was performed on what influence the preoperative neurologic status had on the decision on type of surgery. The rationale behind this analysis is a simple algorithmic decision. Did the complex situation with existing preoperative neurologic impairment, such as hemiparesis, paraparesis, aphasia, or coma, prompt the surgeon to choose a quicker and less-invasive procedure with less anticipated perioperative and early postoperative complications? Even here no difference was seen, with $24.7 \%$ with preoperative neurologic deficit in group A and $31.4 \%$ operated in group $\mathrm{B}(P=.11)$.

End-organ malperfusion and ischemia develop in $16 \%$ to $30 \%$ of patients with $\mathrm{AADA},{ }^{36-40}$ resulting in a postoperative mortality of up to $89 \%$ in patients with a preexisting malperfusion pathology. ${ }^{39}$ Prolonged endorgan ischemia induces a rapid inflammatory cascade, which increases the operative risk dramatically. Different operative strategies have been developed to address this preoperative risk constellation, such as dissection membrane fenestration with subsequent surgical repair after the inflammatory cascade subsides. However, this delays treatment of the dissected aorta, increasing the risk of aortic rupture or dissection-related complications. ${ }^{41}$ Other groups propagate immediate surgical treatment of the dissected aorta with the rationale of restoring perfusion over the true lumen and thus resolving a major group of malperfusion pathology. Fann and colleagues ${ }^{38}$ demonstrated only a minority of patients requiring additional procedures after central aortic repair and a similar rate of mortality in the presence or absence of malperfusion before surgical treatment. The prognosis of patients with preoperative malperfusion remains poor, and prolonged periods of cardiopulmonary bypass and large volume blood resuscitation may contribute to a large capillary leak and end-organ damage. ${ }^{36}$ In view of the patient analysis, $39.7 \%$ of patients presented with a malperfusion deficit, including coronary, spinal, visceral, or peripheral limb ischemia. There was no difference in the onset of new malperfusion deficit after surgical treatment between the 2 groups $(P=.53)$.

\section{CONCLUSIONS}

On analysis of the GERAADA data, it may be concluded that the more extensive treatment with total arch replacement and possibly adjunct therapy of the descending aorta can be performed in patients with AADA at an acceptable operative risk comparable to the standard treatment with replacement of the ascending aorta. Immediate postoperative complications, such as excessive bleeding and frequency of rethoracotomy, are higher; however, the 30-day mortality and onset of new neurologic and malperfusion deficit showed no significant difference. In the absence of preexisting neurologic deficits, subgroup analysis demonstrates a higher mortality for patients treated with total arch replacement.

\section{Study Limitations}

Limitations of the study are clear; factors such as case volume per center, experience of the individual surgeon, aortic wall quality, and institutional philosophy influence the decision for method of treatment and cannot be taken into account in this analysis. The goal of this registry analysis is not to propagate or criticize a more radical aortic arch approach of treatment for AADA. A more conservative surgical treatment of AADA without aortic arch replacement allows consistently good operative results when performed by experienced surgeons. Total arch replacement may contribute to a positive outcome of the proximal descending aorta, but the distal descending aorta and abdominal aorta 
may still be prone to aneurysmal dilation. Long-term results are presently not obtained by the registry data, which are clearly necessary to justify the necessity of possible aortic reintervention for patients treated for AADA by the differing surgical approaches. Modifications of the GERAADA address this issue with yearly follow-up data up to 10 years after surgery included for a more thorough analysis of patients with AADA.

The authors thank the centers participating in the GERAADA: Herzzentrum Leipzig, Klinik für Herzchirurgie, Leipzig, Germany; Universitätsklinikum Frankfurt, Abteilung für Thorax-, Herz- und Thorakale Gefäßchirurgie, Frankfurt am Main, Germany; Universitäres Herz- und Kreislaufzentrum Freiburg - Bad Krozingen, Abteilung für Herz- und Gefäßchirurgie, Freiburg, Germany; Universitätsklinikum Heidelberg, Abteilung für Herzchirurgie, Heidelberg, Germany; Klinikum Augsburg, Klinik für Herz- und Thoraxchirurgie, Augsburg, Germany; Universitätsklinikum Tübingen, Klinik für Thorax-, Herz- und Gefäßchirurgie, Tübingen, Germany; Klinikum der Ludwig-Maximilians-Universität München-Großhadern, Herzchirurgische Klinik und Poliklinik, München, Germany; Universitäres Herzzentrum Hamburg, Klinik und Poliklinik für Herz- und Gefäßchirurgie, Hamburg, Germany; Universitätsmedizin Mainz, Klinik für Herz-, Thoraxund Gefäßchirurgie, Mainz, Germany; Städtisches Klinikum Braunschweig, Klinik für Herz-, Thorax- und Gefässchirurgie, Braunschweig, Germany; Klinikum Oldenburg, Klinik für Herzchirurgie, Oldenburg, Germany; Inselspital Bern, Universitätsklinik für Herz- und Gefässchirurgie, Bern, Switzerland, Herz- und Gefäß-Klinik Bad Neustadt, Abteilung für Kardiochirurgie, Bad Neustadt, Germany; Westdeutsches Herzzentrum Essen, Klinik für Thorax- und kardiovaskuläre Chirurgie, Essen, Germany; Allgemeines Krankenhaus - Universitätskliniken Wien, Abteilung für Herz- und Thoraxchirurgie, Wien, Austria, Universitätsklinikum Ulm, Klinik für Herzchirurgie, Ulm, Germany; SchüchtermannKlinik Bad Rothenfelde, Abteilung für Herzchirurgie, Bad Rothenfelde, Germany; Herzzentrum Dresden, Klinik für Kardiochirurgie, Dresden, Germany; Universitätsklinikum SchleswigHolstein Campus Lübeck, Klinik für Herzchirurgie, Lübeck, Germany; Universitätsklinikum Bonn, Klinik und Poliklinik für Herzchirurgie, Bonn, Germany; Kerckhoff-Klinik, Abteilung für Herz- und Thoraxchirurgie, Bad Nauheim, Germany; Klinikum Nürnberg, Klinik für Herzchirurgie, Nürnberg, Germany Universitätsklinikum Würzburg, Klinik und Poliklinik für Thorax-, Herz- und Thorakale Gefäßchirurgie, Würzburg, Germany; Herzzentrum Duisburg, Klinik für Thorax- und Kardiovaskularchirurgie, Duisburg, Germany; Universitätsklinikum des Saarlandes Homburg, Klinik für Thorax- und Herz-Gefäßchirurgie, Homburg, Germany; Klinikum Kassel, Klinik für Herz-, Thorax- und Gefäßchirurgie, Kassel, Germany; Universitätsklinikum Münster, Klinik und Poliklinik für Thorax-, Herz- u. Gefäßchirurgie, Münster, Germany; Klinikum Passau, Klinik für Herzchirurgie, Passau, Germany; Albertinen-Krankenhaus Hamburg, Abteilung für Kardiochirurgie, Hamburg, Germany; Herz- und Diabeteszentrum Nordrhein-Westfalen, Abteilung für Thorax- und Kardiovaskularchirurgie, Bad Oeynhausen, Germany; Universitätsklinikum Schleswig-Holstein Campus Kiel, Klinik für Herz- und Gefäßchirurgie, Kiel, Germany; Universitätsklinikum Aachen, Klinik für
Thorax-, Herz- und Gefäßchirurgie, Aachen, Germany; Herzzentrum Lahr/Baden, Lahr, Germany; Klinik für Herzchirurgie Karlsruhe, Karlsruhe, Germany; Bundeswehrzentralkrankenhaus Koblenz, Abteilung für Herz- und Gefäßchirurgie, Koblenz, Germany; Schön Klinik Vogtareuth, Klinik für Herzchirurgie, Vogtareuth, Germany; Herz- und Gefäßzentrum Bad Bevensen, Klinik für Herz-Thorax-Chirurgie, Bad Bevensen, Germany; Universitätsklinikum Rostock, Klinik und Poliklinik für Herzchirurgie, Rostock, Germany; Westpfalz-Klinikum Kaiserslautern, Thorax-, Herz- und Gefäßchirurgische Klinik, Kaiserslautern, Germany; Robert-Bosch-Krankenhaus Stuttgart, Klinik für Herzund Gefäßchirurgie, Stuttgart, Germany; Klinikum Fulda, Klinik für Herz- und Thoraxchirurgie, Fulda, Germany; HELIOS Klinikum Wuppertal, Klinik für Herzchirurgie, Herzzentrum, Wuppertal, Germany; Universitätsklinikum Jena, Klinik für Herz- und Thoraxchirurgie, Jena, Germany; Zentralklinik Bad Berka, Klinik für Kardiochirurgie, Bad Berka, Germany; Herzzentrum des Universitätsklinikums Köln, Klinik für Herz- und Thoraxchirurgie, Köln, Germany; MediClin Herzzentrum Coswig, Klinik für Herz- und Gefäßchirurgie, Coswig, Germany; Medizinische Hochschule Hannover, Klinik für Herz-, Thorax-, Transplantations- und Gefäßchirurgie, Hannover, Germany; Sana Herzchirurgische Klinik Stuttgart, Stuttgart, Germany; MartinLuther-Universität Halle-Wittenberg, Universitätsklinik und Poliklinik für Herz- und Thoraxchirurgie, Halle, Germany; and Klinikum Links der Weser Bremen, Klinik für Thorax-, Herzund Gefäßchirurgie, Bremen, Germany.

\section{References}

1. Ehrlich MP, Ergin MA, McCullough JN, Lansman SL, Galla JD, Bodian CA, et al. Results of immediate surgical treatment of all acute type A dissections. Circulation. 2000;102(19 Suppl 3):III248-52.

2. Ergin MA, Phillips RA, Galla JD, Lansman SL, Mendelson DS, Quintana CS, et al. Significance of distal false lumen after type A dissection repair. Ann Thorac Surg. 1994;57:820-4.

3. Geirsson A, Bavaria JE, Swarr D, Keane MG, Woo YJ, Szeto WY, et al. Fate of the residual distal and proximal aorta after acute type A dissection repair using a contemporary surgical reconstruction algorithm. Ann Thorac Surg. 2007;84: 1955-64.

4. Bachet J, Goudot B, Dreyfus GD, Brodaty D, Dubois C, Delentdecker P, et al. Surgery for acute type A aortic dissection: the Hopital Foch experience (19771998). Ann Thorac Surg. 1999;67:2006-9.

5. Moore NR, Parry AJ, Trottman-Dickenson B, Pillai R, Westaby S. Fate of the native aorta after repair of acute type A dissection: a magnetic resonance imaging study. Heart. 1996;75:62-6.

6. Heinemann M, Laas J, Karck M, Borst HG. Thoracic aortic aneurysms after acute type A aortic dissection: necessity for follow-up. Ann Thorac Surg. 1990;49:580-4.

7. Yeh CH, Chen MC, Wu YC, Wang YC, Chu JJ, Lin PJ. Risk factors for descending aortic aneurysm formation in medium-term follow-up of patients with type A aortic dissection. Chest. 2003;124:989-95.

8. Bachet J, Teodori G, Goudot B, Diaz F, el Kerdany A, Dubois C, et al. Replacement of the transverse aortic arch during emergency operations for type A acute aortic dissection. Report of 26 cases. J Thorac Cardiovasc Surg. 1988;96:878-86.

9. Fann JI, Smith JA, Miller DC, Mitchell RS, Moore KA, Grunkemeier G, et al. Surgical management of aortic dissection during a 30-year period. Circulation. 1995;92(9 Suppl):II113-21.

10. Kazui T, Kimura N, Yamada O, Komatsu S. Total arch graft replacement in patients with acute type A aortic dissection. Ann Thorac Surg. 1994;58:1462-8.

11. Kazui T, Washiyama N, Muhammad BA, Terada H, Yamashita K, Takinami M, et al. Extended total arch replacement for acute type A aortic dissection: experience with seventy patients. J Thorac Cardiovasc Surg. 2000;119:558-65.

12. Sun LZ, Qi RD, Chang Q, Zhu JM, Liu YM, Yu CT, et al. Surgery for acute type A dissection using total arch replacement combined with stented elephant trunk 
implantation: experience with 107 patients. J Thorac Cardiovasc Surg. 2009;138: 1358-62.

13. Uchida N, Shibamura H, Katayama A, Shimada N, Sutoh M, Ishihara H. Operative strategy for acute type A aortic dissection: ascending aortic or hemiarch versus total arch replacement with frozen elephant trunk. Ann Thorac Surg. 2009;87: 773-7.

14. Crawford ES, Kirklin JW, Naftel DC, Svensson LG, Coselli JS, Safi HJ. Surgery for acute dissection of ascending aorta. Should the arch be included? J Thorac Cardiovasc Surg. 1992;104:46-59.

15. Ohtsubo S, Itoh T, Takarabe K, Rikitake K, Furukawa K, Suda H, et al. Surgical results of hemiarch replacement for acute type A dissection. Ann Thorac Surg. 2002;74:S1853-63

16. Westaby S, Saito S, Katsumata T. Acute type A dissection: conservative methods provide consistently low mortality. Ann Thorac Surg. 2002;73:707-13.

17. Weigang E, Conzelmann LO, Kallenbach K, Dapunt O, Karck M. German Registry for Acute Aortic Dissection Type A (GERAADA)—lessons learned from the registry. J Thorac Cardiovasc Surg. 2010;58:154-8.

18. Weigang E, Görgen C, Kallenbach K, Dapunt O, Karck M. German Registry for Acute Aortic Dissection Type A (GERAADA) - new software design, parameters and their definitions. J Thorac Cardiovasc Surg. 2011;59:69-77.

19. Weigang E, for the GERAADA study group. Registro Alemán de la Disección Aguda de Aorta Tipo A (GERAADA)-German Registry for Acute Aortic Dissection Type A (GERAADA). Circ Cardiovasc. 2009;16:231-4

20. Conzelmann LO, Dapunt O, Kallenbach K, Karck M, Weigang E. Deutsches Register für akute Aortendissektion Typ A (GERAADA) - Motiv, Entwicklung, erste Erkenntnisse und Vision. Z Herz Thorax Gefäßchir. 2009; 23:298-304.

21. Immer FF, Krähenbühl E, Hagen U, Stalder M, Berdat PA, Eckstein FS, et al. Large area of the false lumen favors secondary dilatation of the aorta after acute type A aortic dissection. Circulation. 2005;112(9 Suppl):I249-52.

22. Hirotani T, Nakamichi T, Munakata M, Takeuchi S. Routine extended graft replacement for an acute type A aortic dissection and the patency of the residual false channel. Ann Thorac Surg. 2003;76:1957-61.

23. Takahara Y, Sudo Y, Mogi K, Nakayama M, Sakurai M. Total aortic arch grafting for acute type A dissection: analysis of residual false lumen. Ann Thorac Surg. 2002;73:450-4.

24. Urbanski PP, Siebel A, Zacher M, Hacker RW. Is extended aortic replacement in acute type A dissection justifiable? Ann Thorac Surg. 2003;75:525-9.

25. Miyamoto S, Hadama T, Anai H, Wada T, Iwata E, Tanaka H, et al. Simplified elephant trunk technique promotes thrombo-occlusion oft the false lumen in acute type A aortic dissection. Ann Thorac Cardiovasc Surg. 2006;12:412-6.

26. Watanuki H, Ogino H, Minatoya K, Matsuda H, Sasaki H, Ando M, et al. Is emergency total arch replacement with a modified elephant trunk technique justified for acute type A aortic dissection? Ann Thorac Surg. 2007;84:1585-91.
27. Tsagakis K, Pacini D, Di Bartolomeo R, Benedik J, Cerny S, Gorlitzer M, et al. Arch replacement and downstream stent grafting in complex aortic dissection: first results of an international registry. Eur J Cardiothorac Surg. 2011;39:87-93.

28. Sabik JF, Lytle BW, Blackstone EH, McCarthy PM, Loop FD, Cosgrove DM. Long-term effectiveness of operations for ascending aortic dissections. J Thorac Cardiovasc Surg. 2000;119:946-62.

29. Dobrilovic N, Elefteriades JA. Stenting the descending aorta during repair of type A dissection: technology looking for an application? J Thorac Cardiovasc Surg. 2006;131:777-8.

30. Kim JB, Chung CH, Moon DH, Ha GJ, Lee TY, Jung SH, et al. Total arch repair versus hemiarch repair in the management of acute DeBakey type I aortic dissection. Eur J Cardiothorac Surg. 2011 Feb 9 [Epub ahead of print].

31. Rylski B, Suedkamp M, Beyersdorf F, Nitsch B, Hoffmann I, Blettner M, et al Outcome after surgery for acute aortic dissection type A in patients over 70 years data analysis from the German Registry for Acute Aortic Dissection Type A (GERAADA). Eur J Cardiothorac Surg. 2011 Jan 19 [Epub ahead of print].

32. Hoefer D, Ruttmann E, Riha M, Schobersberger W, Mayr A, Laufer G, et al. Factors influencing intensive care unit length of stay after surgery for acute aortic dissection type A. Ann Thorac Surg. 2002;73:714-8.

33. Cambria RP, Brewster DC, Gertler J, Moncure AC, Gusberg R, Tilson MD, et al. Vascular complications associated with spontaneous aortic dissection. J Vasc Surg. 1988;7:199-209.

34. Ergin MA, Galla JD, Lansman S, Griepp RB. Acute dissections of the aorta. Current surgical treatment. Surg Clin North Am. 1985;65:721-41.

35. Kallenbach K, Oelze T, Salcher R, Hagl C, Karck M, Leyh RG, et al. Evolving strategies for treatment of acute aortic dissection type A. Circulation. 2004; 110(11 Suppl. 1):II243-9.

36. Girardi LN, Krieger KH, Lee LY, Mack CA, Tortolani AJ, Isom OW. Management strategies for type A dissection complicated by peripheral vascular malperfusion. Ann Thorac Surg. 2004;77:1309-14.

37. Borst HG, Laas J, Heinemann M. Type A aortic dissection: diagnosis and management of malperfusion phenomena. Semin Thorac Cardiovasc Surg. 1991;3:238-41.

38. Fann JI, Sarris GE, Mitchell RS, Shumway NE, Stinson EB, Oyer PE, et al. Treatment of patients with aortic dissection presenting with peripheral vascular complications. Ann Surg. 1990;212:705-13.

39. Deeb GM, Williams DM, Bolling SF, Quint LE, Monaghan H, Sievers J, et al. Surgical delay for acute type A dissection with malperfusion. Ann Thorac Surg. 1997;64:1669-75.

40. Lauterbach SR, Cambria RP, Brewster DC, Gertler JP, Lamuraglia GM, Isselbacher EM, et al. Contemporary management of aortic branch compromise resulting from acute aortic dissection. J Vasc Surg. 2001;33:1185-92.

41. Patel HJ, Williams DM, Dasika NL, Suzuki Y, Deeb GM. Operative delay for peripheral malperfusion syndrome in acute type A aortic dissection: a long-term analysis. J Thorac Cardiovasc Surg. 2008;135:1288-95. 